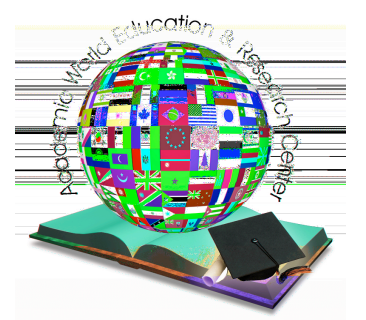

www.awer-center/gjit

\title{
Analysing Bangladeshi consumers' e-commerce security and privacy satisfactions in small to mid-sized enterprises (SMEs)
}

Ergun Gide*

Shakir Karim,

Suggested Citation:

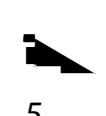

A

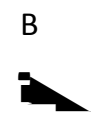

C

C
A

A

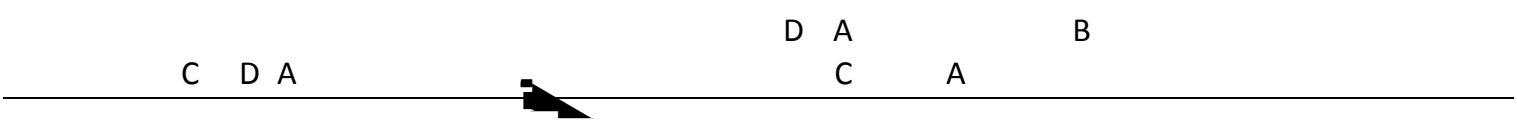

Abstract

B
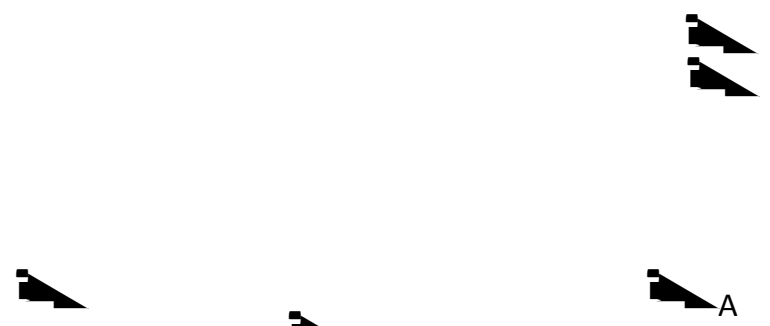

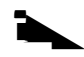

A

B

B

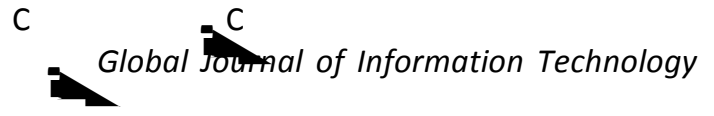

C 
$\begin{array}{ccc}\text { A } & \text { B } & C \\ \text { Global Journal of Information Technology } 5\end{array}$

1. Introduction

C

B

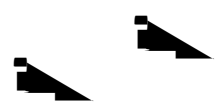

B

B

1.2 Objectives

$\bullet$

B

$\bullet$

$\bullet$

$\bullet$

- $\mathrm{C}$

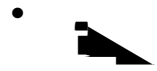

• B
B

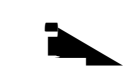

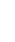

1.3 Aim of the Study

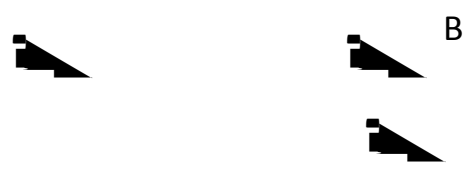

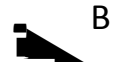

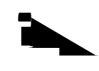

11 
Global Journal of Information Technology 5

1.4 Research Questions
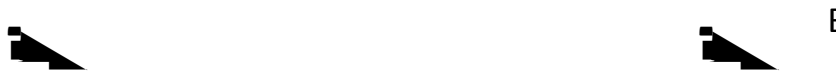

B

B

B
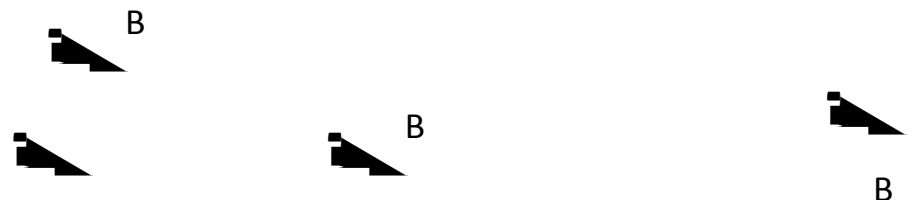

B

1.5 Significance of the Study

2. Literature Review

B

C

BC

2.1 The Technological Dimensions of E-commerce
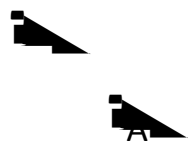

D

A
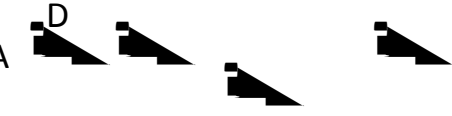

D

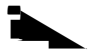

2.2 The Existing Situation and Potential of E-Commerce 


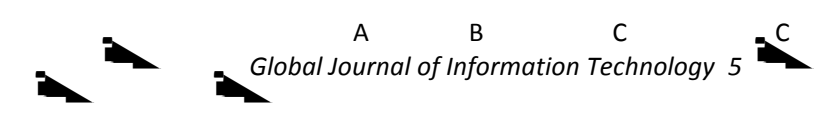

2.3 Internet Usage and E-commerce Industry in Bangladesh

B

B

B
B

C

B

B

\begin{tabular}{ccccc} 
& & $B$ & $C$ & $D$ \\
\hline & $C$ & & $A$ & \\
\hline & & & $D$ \\
\hline & & $A$
\end{tabular}

2.4 E-commerce Sector in Bangladesh

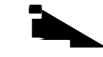

B

D

B

B

- $B$

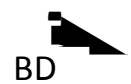

B A

B

-

B

- $\mathrm{B}$

- $A$

- C BD B

2.5 Major Constraints to E-Commerce in Bangladesh

- A

- $A$

-

- 


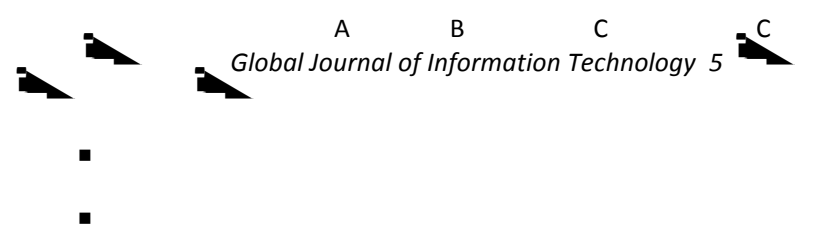

2.6 Present Situation of Cyber Crime in Bangladesh

B

A B $\quad$ B

A

$A B$

$A B$

B

A

\section{Methodology}

3.1 The Strategy

3.2 Document Analysis 
Global Journal of Information Technology 5

C

A

B

3.4 Data Analysis

A

4. Data Collection and Research Analysis

4.1 Qualitative Results

A

A A A A 


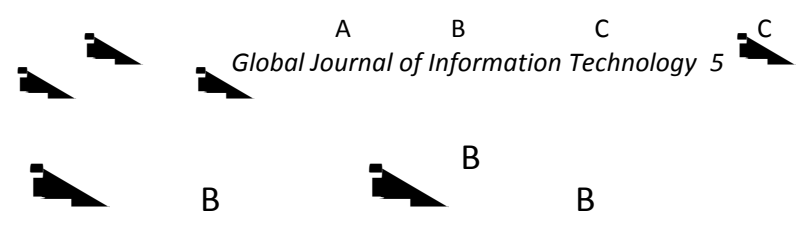

5. Research Results and Key Findings

B

B

B

B

- $\quad B$

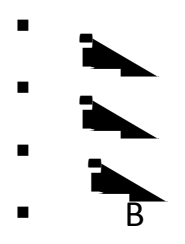

- $A$

6. Conclusion \& Recommendation 


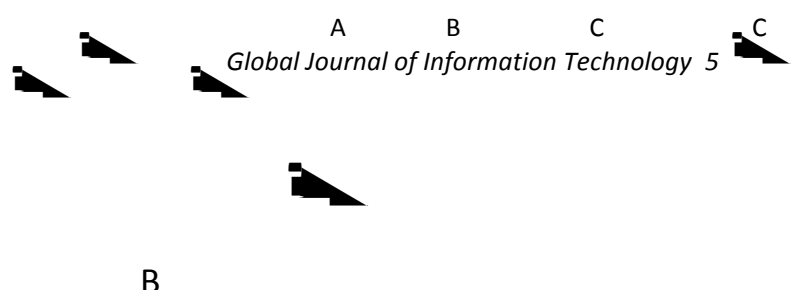

- $B$

\section{C}

-

B

- $\mathrm{B}$
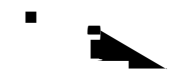

\section{References}

A

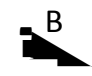

B

A Journal of Business and Economics, 1

A International Journal of Computer anaresearch and Reviews in Computer Engineering 1

University Journal 2 A $\mathrm{C}$ University Journal 2
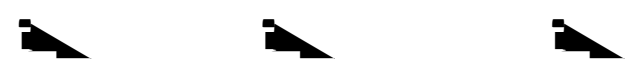

C

D

Information Technology in Bangladesh

E-commerce in Bangladesh

A $\mathrm{D}$

D COIS 19701: Research Methods: Study Guide C

D

A

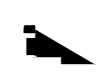

A

Interrmetional Journal of E-Commerce 9 